\title{
A arte da lata: uma crítica à estética da "gambiarra" ou como tecer uma análise crítica sem utilizar os discursos da precariedade e da provisoriedade
}

\begin{abstract}
RESUMO: O presente artigo tem como eixo conceitual uma breve revisão crítica do uso de termos como "precariedade", "provisoriedade" e "gambiarra" disseminados pela crítica de arte oficial para caracterizar um conjunto de obras de arte contemporânea cuja materialidade dialoga com o uso de materiais considerados não-nobres. Através de uma abordagem pós-colonialista e tomando como estudo de caso uma série de obras do artista visual Raimundo Rodriguez, em que o uso de materiais descartados como latas de tintas servem de matéria-prima fundamental para a construção de inúmeros objetos, tornar-se-á visível os limites e problemas conceituais levantados pelos termos mencionados.
\end{abstract}

PALAVRAS-CHAVE: estudos pós-coloniais, crítica de arte, identidade cultural

ABSTRACT: The present article shows, as a conceptual point, a brief art critique revision about the current use of terms such as precariousness, temporary and gambiarra spread by the official art criticism to describe a bunch of contemporary art works, whose materiality dialogues directly with the common use of substances considered not nobles. Transversely a post-colonialist approach and taking as a case study some Raimundo Rodriguez's work arts, wherein discarded materials as paint-boxes may be used as fundamental feedstock to construct several objects, the limits and conceptual problems taking by the mentioned terms, would be more perceptible.

KEYWORDS: post-colonial studies, art criticism, cultural identity

\footnotetext{
* Renata Gesomino é professora adjunta do IART-UERJ. Doutora em História e Crítica da Arte pelo PPGAV-UFRJ. Mestre em História e crítica da arte pelo PPGAV-UFRJ, graduada em artes plásticas, pintura, pela EBA-UFRJ. Tem experiência na área de artes visuais com ênfase em pintura, estudos pós-coloniais e nas relações entre arte e política. Atualmente produz textos e resenhas críticas exercendo a atividade como crítica de arte e curadora independente.
} 
"Não podem representar-se, tem que ser representados."

Karl Marx, O 18 Brumário de Luís Bonaparte. ${ }^{1}$

Uma das principais questões referentes ao uso ambivalente, e, por vezes pejorativo de termos como: "precariedade", "provisoriedade" e "gambiarra", encontradas na crítica de arte brasileira contemporânea, resumem-se em como evitar o deslocamento de um discurso crítico pretensamente imparcial em direção a um discurso colonialista, que inclui a elaboração do estereótipo ${ }^{2}$ e, por conseguinte, da discriminação. Isto é, consiste em um desafio de proporções hercúleas a tentativa de se operar uma sóbria revisão de uma parcela da crítica da arte contemporânea brasileira, esquivando-se do uso de tais termos, no confronto às complexidades apresentadas por certas obras. Se seguíssemos as orientações teóricas de autores como Homi K. Bhabha, no livro O local da cultura, seria possível compreender a extensão dos danos provocados pelo uso subjetivo dos termos mencionados, reconhecendo a potência negativa e não ingênua que pode ser encontrada na falta de acolhimento e na simplificação da alteridade por trás de determinadas classificações.

Para que o problema levantado ganhe mais clareza dialética cabe fazer a seguinte pergunta, uma vez que o discurso do colonialismo parte de polarizações e de um estado de fixidez: Se existe uma arte que pode ser definida a partir do estereótipo presente em palavras como a "precariedade", "provisoriedade" e a ideia ou conceito de "gambiarra" existe, portanto, uma arte que seja genuinamente o seu oposto? A resposta encontrada nas elaborações de um discurso do colonialismo é afirmativa: Para uma arte formulada a partir da ideia de precariedade e provisoriedade existe outra que não é precária nem tampouco provisória. $O$ mesmo pode-se afirmar a respeito do conceito de "gambiarra", que em outras palavras, significa uma solução provisória, isto é, resultante de uma condição de falta ou ausência. Trata-se de um estado ulterior de adversidade e por fim, de precariedade. O conceito de "gambiarra", neste contexto, funcionaria como uma amálgama da precariedade e da provisoriedade, e implicitamente, apresentar-se-ia como uma solução (estética?) de validade efêmera e duvidosa. Esta efemeridade estética representaria em si um grande paradoxo para a própria definição (tradicional) de obra de arte (cuja pretensão é a de ser atemporal) desqualificando-a ou até mesmo despotencializando-a. 
Refutam tais designações críticas e seu respectivo uso,como termos estigmatizadores, apontando aspectos depreciativos, artistas como Ronald Duarte e Raimundo Rodriguez.Duarte, conhecido por executar uma série de intervenções urbanas, mas também, por trabalhar a materialidade plástica de garrafas pet descartadas, responde quando indagado sobre a relação entre suas obras e o conceito de "gambiarra" desenvolvido por críticos como Lisette Lagnado:

Acho que isso aí é uma falácia. A Lisette Lagnado, com essa história dela, a gambiarra, tentando explicar (...) ih, nada disso! Isso aí é o seguinte: o sapo pula por necessidade. É o seguinte: o barraco do Hélio Oiticica e a Tropicália foram pensados em cima da necessidade daquele que pensou primeiro. Quer dizer, o barraco do Jarbas Lopes também, as faixas e tudo, é tudo pensado e direcionado, não tem nada de gambiarra.Está tudo muito bem feito, (repete) não tem precariedade nenhuma! Inclusive, São Precário é na Itália! Eu fiz a Nuit Blanche, tinha lá o São Precário, porque aí, todo mundo na Nuit Blanche, vem com esse discurso da precariedade, porque ninguém tem dinheiro pra poder fazer arte, então, faz qualquer merda? Não, não senhor, eu não faço qualquer merda! Mesmo quando trabalho com o resto da cidade, eu não faço qualquer merda. $\mathbf{O}$ meu barraco é o meu melhor barraco!Não tem nada de gambiarra! É fazer com o que se tem, e com aquilo que se acredita que tenha mão pra fazer, é o que eu posso, o que eu sei fazer. (grifo nosso) ${ }^{3}$

E complementa o artista cearense, Raimundo Rodriguez, quando indagado sobre as mesmas possíveis classificações estéticas e formais de seu trabalho:

O meu interesse é muito mais simbólico, é muito anterior, num sentido atávico mesmo.É que eu acredito que as energias desses materiais são muito maiores que de um material industrializado que eu vou comprar na loja. Mas, isso não significa também que um dia eu não pegue um material se ele me falar mais alto e eu adquirir esse material. Só que eu desenvolvi dentro da minha pesquisa, dentro da minha proposta de trabalho, encontrar essas coisas que passem pelo meu caminho, e que tenham essa energia já deixada por alguém. Agora, "gambiarra", essas estéticas, esses nomes, foram criados e ficou divertido, acharam que ficou bonitinho, mas, me parece uma coisa de minimizar uma "forma", sabe? Art Povera, poxa, você pode ter Art Povera boa e ruim. (grifo nosso) ${ }^{4}$

Parece claro no depoimento de ambos que a livre escolha do repertório material e temático se dá por um mecanismo de seleção simbólica consciente e intencional (uma poiesis) e não por uma operação de substituição momentânea de um material "pobre"/precário, "substituível"/ provisório, e decadente por outro. Ambos acreditam que suas obras têm uma capacidade 
potencializadora, isto é, afirmativa. Portanto, o conceito estético de provisoriedade e de precariedade que o material dito "não-nobre" poderia evocar é percebido como uma estratégia ideológica de caráter ambíguo.

Um dos questionamentos mais pertinentes, segundo Bhabha, situa-se na compreensão do modo de representação de uma alteridade e como, este modo de representação, está sendo julgado, normativamente, na formulação de certos discursos culturais hegemônicos. Decerto um texto crítico representa, entre outros aspectos, a manifestação de um poder político e ideológico dominante. Todavia, para a presente análise da "arte da lata" empregada e desenvolvida especificamente por Raimundo Rodriguez, pretende-se, assumir uma postura crítica pós-colonial ${ }^{5}$, e, para tal, segundo Bhabha, as análises teóricas devem ser realizadas da seguinte maneira:

Isto demanda uma revisão radical da temporalidade social na qual histórias emergentes possam ser escritas; demanda também a rearticulação do "signo" no qual se possam inscrever

identidades culturais. E a contingência como tempo significante de estratégias contra-hegemônicas não é uma celebração da "falta" ou do "excesso", ou uma série autoperpetuadora de ontologias negativas. Esse "indeterminismo" é a marca do espaço conflituoso mas produtivo, no qual a arbitrariedade do signo de significação cultural emerge no interior das fronteiras regulares do discurso social. (grifo nosso). (BHABHA, 2010, p. 241-242)6

O signo da lata, neste sentido, não poderia ser descrito apenas pela retórica do "material não-nobre", refletindo, por outro lado, as manifestações de uma identidade territorial fronteiriça, que se articula não pelo viés exclusivo da pobreza socioeconômica, mas, aderindo às conotações mais positivas, causando certa indeterminação. Todavia, reconhece-se, na lata, apenas a matéria-prima e bruta com a qual o artista voluntariamente decidiu trabalhar. O material que abunda no entorno na forma de objetos reapropriados revela o descarte realizado nas áreas de periferia, melhor dizendo, nos arredores de Três Corações, bairro onde vive o artista. Entretanto, não devemos encarar a atividade, quase arqueológica, de recolhimento e resgate de tais materiais como uma pré-condição - e seria precisamente neste instante que se validaria o discurso da precariedade que se desenvolve a partir da percepção de uma carência por materiais "nobres", tradicionais - e, sim, como foi dito, como uma escolha consciente pelo que há de disponível no entorno e é percebido por seu potencial afirmativo oculto. 
Nas séries de obras em progresso intituladas "Latifúndios" e nas exposições "Sonhos" e "Obras Inéditas", a análise dos trabalhos pretende esquivar-se das armadilhas contidas na ambiguidade discursiva das estéticas da gambiarra, da precariedade e provisoriedade, na contramão dos discursos críticos de tendência colonialista, reinscrevendo a lata enquanto signo cultural nas indeterminações que atravessam os processos de alteridade.

Não se pode considerar, portanto, a escolha inicial de Rodriguez por um material dito "não-nobre" como a lata, como uma articulação "provisória" ou "precária", definidora do valor simbólico e estético ulterior de seu trabalho. O "Latifúndio", por sua vez, é um neologismo criado por Rodriguez, para nomear uma vasta série de trabalhos feitos particularmente com a lata e que, ironicamente, significa o monopólio territorial da lata ou uma concepção de território demarcado que é feito poeticamente com latas de tintas.

Dando continuidade à série de trabalhos que foi construída através de uma ocupação ostensiva do espaço disponível com objetos variados, o artista, desenvolveu pela primeira vez a montagem da exposição intitulada "Sonhos" em 2007, na extinta Galeria 90, criando um ambiente caótico e onírico. O percurso da exposição se iniciava com a ocupação de duas paredes opostas que eram confrontadas imageticamente, formando dois ambientes: um abstrato feito com a série dos "Latifúndios" e, que representava, segundo o artista, a visão aérea, como as imagens produzidas por um satélite, de cidades sonhadas; o outro, coberto integralmente pelas "sobras do mundo"7 feito a partir da série "Reflexões sobre questões materiais e transitórias". Este ambiente representava a visão aproximada dentro das mesmas cidades sonhadas a partir de sua materialidade objetual. No corredor, ao fundo, repousavam a escultura de um cavalo feita de lata, papelão, madeira, entre outros materiais, juntamente com um oratório centralizado. Uma terceira sala apresentava, por fim, a entrada na cidade sonhada, sendo a instalação constituída, portanto, de três momentos significativos. Segundo Rodriguez, o ambiente criado simbolizava a diversidade onírica encontrada nas experiências afetivas fragmentadas dos habitantes das cidades. Tais sonhos ganharam a materialidade de vários rádios de pilha, cada um sintonizado numa estação com perfil musical distinto; funk, música gospel/ evangélica, rock, samba, entre outros. Contudo, ao atingir às $19 \mathrm{~h}$ da noite todos os rádios reproduziam os informes do programa "A voz do Brasil." 
Mais uma vez, simbolicamente, este seria o momento em que o país se unificaria através da emissão de uma mensagem em uníssono. Em outras palavras, ouvia-se em cadeia nacional a mesma mensagem, ainda que durante um curto espaço de tempo, unificando e, quiçá, anulando, supostamente, as pluralidades identitárias que foram representadas pelas diversas estações de música. De certa maneira, cabe ressaltaras semelhanças entre a mencionada instalação de Rodriguez e a de Cildo Meireles,intitulada Babel (2001-2006) realizada, portanto, anteriormente. Em Babel, o que pode ser visto é um grande projeto onde uma torre de cinco metros é formada a partir do empilhamento de cerca de 900 tipos de aparelhos de rádio, todos sintonizados em estações diferentes, gerando um som caótico, que intencionava representar o som igualmente entrópico e plural das grandes cidades pelo mundo. A instalação era apresentada em um ambiente escuro, onde as luzes dos aparelhos cumpriam uma função secundária, mas não menos importante. No caso da obra de Cildo Meireles, foram acentuadas as diferenças culturais entre os povos e o multiculturalismo foi abordado a partir da paródia 
sugerida pelo próprio nome da instalação. Estas são algumas das questões mais explorada na análise da obra em questão, por críticos, cuja abordagem também se encontra pautada nas formulações do discurso pós-colonialista, como Moacir dos Anjos, por exemplo, que chegou a afirmar que em Babel:

[...] o visitante logo identifica, ainda que de modo impreciso, um ruído baixo e contínuo e contornos de uma estrutura cônica, onde divisa muitas e pequenas fontes de luz. Atraído pelo volume disposto no centro da sala e envolto em quase penumbra, circula em torno dessa estrutura e percebe, por fim, tratar-se de uma torre - mais de dois metros de diâmetro e cerca de cinco metros de altura - feita do acúmulo e da sobreposição de centenas de rádios.[...]

O fato de esses sons de origens diversas estarem reunidos em um só canto parece aludir à existência de um espaço de negociação - simbólico, econômico e político. Espaço de estabelecimento e contínua reelaboração, por meio de processos de expressão humana, de distinção de povos. (ANJOS, 2010, p. 81) ${ }^{9}$

Nesse tocante, tal qual sugerido por Bhabha, Moacir dos Anjos introduz uma "revisão radical da temporalidade social na qual histórias emergentes possam ser escritas," por meio de uma análise da materialidade dos objetos-signos formadores da obra - os rádios (que representam, em última instância, a veiculação de culturas e tempos diversos), explicitando as diferenças dos recursos tecnológicos apontadas como diferenças socioeconômicas, para além das distinções multiculturais. Desta maneira, o crítico reiterou sua abordagem pós-colonial que travessou, indiscutivelmente, questões políticas e ideológicas:

Ainda que ocupem o mesmo espaço na sala expositiva e façam uso das mesmas vias de transmissão, esses tantos rádios diferentes aludem à presença simultânea, entre povos diversos ou no interior de uma mesma nação, de tempos sociais distintos. Simbolizam, dessa maneira,

a distribuição assimétrica do poder que permite afirmar soberanias e o comando descentralizado, mas efetivo, dos mecanismos que estruturam permutas entre lugares diferentes. (ANJOS, 2010, p. 83). (grifo nosso) $)^{10}$

Por outro lado, na instalação "Sonhos" proposta por Rodriguez, a busca parecia ser a da confraternização e/ou aceitação das diferenças culturais, sociais e políticas, ainda que de forma irônica, pelas imposições ideológicas, e culturais de uma transmissão autoritária, em cadeia nacional, exemplificada pela veiculação do programa "A voz do Brasil." Em certo sentido, a 
transmissão remontava, anacronicamente, à época do Estado Novo no Brasil, sob a tutela do governo de Getúlio Vargas, em que se originou o programa similar "Hora do Brasil"."1 Tal iniciativa do governo getulista, que ficou conhecida popularmente na época como "fala sozinho", caracterizava-se ainda como uma tática de manipulação da informação. A "interrupção" provocada pela transmissão do programa "A voz do Brasil", no terceiro ambiente da exposição pode ser compreendida, estrategicamente, como o momento em que, tal como na "Babel" de Meireles, pretendia-se revisar uma temporalidade social, reinscrevendo histórias emergentes, no caso, "sonhadas" ou até mesmo recordadas da infância do artista, no âmbito das indeterminações.

Com efeito, retornando à questão técnica nas formulações das poéticas da lata, sabe-se que o artista deu início às pesquisas especificamente com a lata a partir do ano 2000, trabalhando em um processo singular de abertura, planificação e desamasso das latas. Neste processo desenvolveu uma técnica peculiar de "costura" de pedaços que eram posteriormente esticados, às vezes unidos com arames, outras com parafusadeira, transformando o material indócil em superfície maleável. Passada a etapa de preparação e conversão das latas em suporte, o material era usado na criação de "pinturas planas" e também em esculturas geométricas e figurativas. Curiosamente Rodriguez não interferia diretamente na lata, preservando o testemunho de suas cores originais. Com o avanço nas experiências com a lata, o artista construiu toda uma série de esculturas feitas predominantemente a partir do referido material. As mais importantes e que ganharam maior visibilidade, talvez tenham sido as de temática sacra; as imagens de São Jorge montado em seu cavalo.

Tais esculturas, com inúmeras versões do mesmo tema, foram apresentadas, posteriormente, em eventos teatrais como "Salve Jorge: O Intrépido Santo do Povo" ocorrido em 2010, na Igreja N. S. de Fátima, em Nova Iguaçu e, também em Nilópolis. Em seguida, outra versão que se enquadraria numa categoria de "escultura cinética", foi elaborada pelo artista para integrar a comissão de frente da Escola de Samba Beija-Flor de Nilópolis, durante o desfile de carnaval em 2013. Deste modo, Rodriguez, foi se consolidando no meio artístico, como um artista exímio na manipulação poética da linguagem plástica da lata.

Nota-se que a materialidade dos objetos que foram aplicados para compor o corpo da imagem sacra e do dragão, revela o uso de tampas de latas de tintas que foram recortadas simulando 


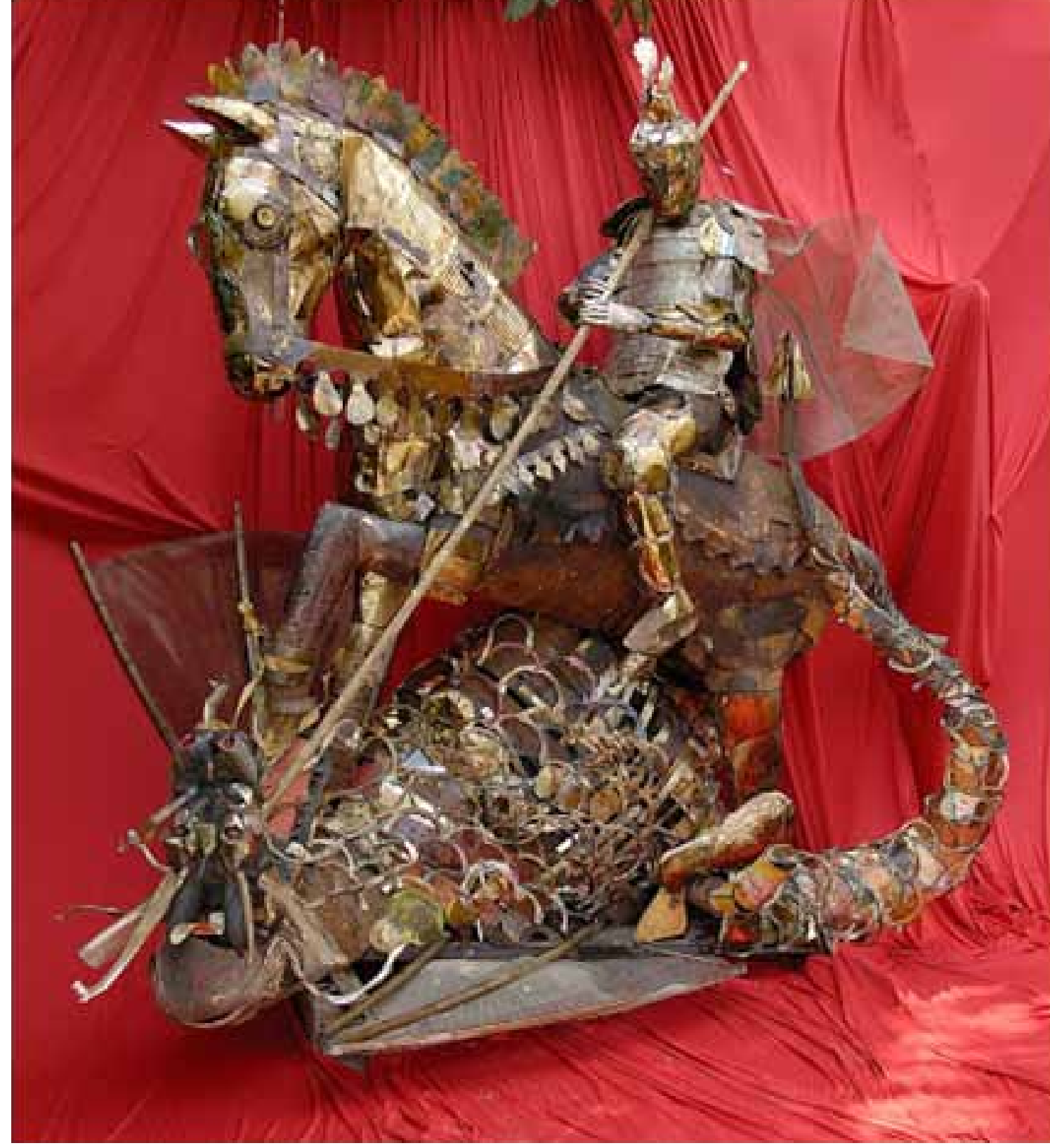

Raimundo Rodriguez

São Jorge Vencedor

2007 Foto: Ac. Junior 
grandes escamas. Chapinhas de garrafas de bebidas foram coladas para compor a armadura de São Jorge, produzindo seu brilho metálico, enquanto que o corpo do cavalo era feito basicamente de papelão que foi recoberto com cera e betume, conferindo o efeito de uma couraça envelhecida. Todavia, as obras pertencentes à série específica dos "Latifúndios", enquanto suportes, passaram a ser cada vez mais utilizadas na composição de grandes estruturas abstratas coloridas que lembravam as pinturas planas em estilo semelhante ao Colorfield ${ }^{12}$ (campos de cor) e poderiam ser indefinidamente remontadas.

Neste momento, seria instaurada a rearticulação da lata enquanto signo que promove a indeterminação de certas identidades culturais conflitantes. A transfiguração estética da lata não a reduz a um signo de pobreza; não havendo desta forma o reconhecimento automático do precário nem tampouco do provisório. A ressignificação ou transfiguração da lata resulta, de fato, em uma ontologia afirmativa, fazendo com que tais abordagens críticas (gambiarra, provisoriedade e precariedade) se tornem incompatíveis com a obra do artista. Algumas versões semelhantes da exposição "Sonhos" tiveram passagens contínuas por inúmeros SESCs, destacando a realização de montagens diversas, principalmente, aquelas voltadas para a apresentação ao público das áreas periféricas. Em uma dessas versões, a exposição foi realizada, estrategicamente, durante as comemorações do "Dia da Baixada Fluminense", ocorrida no dia 31 de maio de 2011, no SESC de Duque de Caxias. As obras apresentadas na montagem em questão, compuseram um conjunto total de aproximadamente 40 módulos, pertencentes à série "Latifúndios",que foram justapostos formando uma grande paisagem com cores desgastadas feitas predominantemente de latas de tintas e papelão. Ocupando as paredes da galeria uniformemente os "latifúndios" do artista, demarcaram as riquezas de um território específico; a Baixada Fluminense. É, nesta construção de um discurso imagético apreciativo que a obra de Rodriguez pode escapar de alguns estereótipos conceituais, frequentes, no discurso crítico contemporâneo tais como: "gambiarra" e "art povera." Evita-se, portanto, o uso do termo "Arte Povera", pois este se refere imediatamente a um conjunto de obras desenvolvidas na década de 70 e, principalmente, por artistas italianos, que elegeram os materiais "pobres" (trapos, matéria orgânica, lixo em geral), como uma estratégia de confronto às formas tradicionais e canônicas da arte, numa tentativa de estabelecer à sua maneira o conceito de "arte e vida". Deste modo, os artistas italianos conceituados pelo crítico Germano Celant, tentaram levantar alguns questionamentos mais polêmicos acerca do comportamento da sociedade de consumo europeia. 
A Arte Povera tratou de um confronto direto entre um passado clássico italiano envolto em tradição, e, segundo Michael Archer, "a miscelânea contingente do presente". (ARCHER, 2001, p. 91), questões estas, que não poderiam ser apontadas na obra de Rodriguez, uma vez que não se trata de assumir o signo da pobreza através do uso de certos materiais com o objetivo de confrontar uma tradição que sequer possuímos, mas, principalmente, debater a afirmação de uma alteridade. Neste contexto atual, a comparação com a Arte Povera poderia agregar conotações ambíguas, uma vez que estaria deslocada de seu contexto histórico e cultural original, conduzindo a análise ao estereótipo ou a uma rude simplificação estética.

Na obra intitulada "Brasil", feita em 2006, Rodriguez desenvolveu um objeto híbrido, por meio de técnica mista que transformava um conjunto de latas de tintas abertas, amassadas, costuradas e pregadas com parafusadeira elétrica, em um aglomerado multiforme e colorido que remetia diretamente ao contorno da cartografia do Brasil. Esse (não)objeto agregou características tanto da pintura quanto da escultura e apresentava uma silhueta sarcástica de um Brasil composto uniformemente de lata. Neste trabalho, pode-se identificar uma tendência do artista em pensar o local de maneira crítica e engajada, para além de uma abordagem valorativa das identidades periféricas. O uso simbólico da lata como metáfora visual das questões pendentes relativas ao passado colonial problemático brasileiro é sugerido. Neste contexto, a lata simularia a expansão socioeconômica e cultural de um território vasto em processo de lento desenvolvimento, tal como ocorreu com a nossa modernização nas primeiras décadas do século XX. O material usado em "Brasil" seria, pois, o signo também de uma expressão imagética ambivalente, visto que ao mesmo tempo em que poderia dialogar com o desuso e o descarte exemplificados uniformemente através da materialidade da lata, que ocupa todo o território nacional, representaria a sua vastidão e capacidade transformadora, ao passar de material literal/rejeitado para material simbólico/desejado, não se fixando em nenhuma posição extrema. Em outras palavras, na obra "Brasil", ou mais precisamente, o grande "latifúndio Brasil" poderia remeter também à distribuição (des)igual das riquezas e de terras - problema crônico que se arrasta ao longo dos séculos de crescimento desordenado das cidades brasileiras, marco de nosso próprio subdesenvolvimento, ainda não superado. Toda obra de Rodriguez, pode ser identificada a partir de um impulso transcendente que visa harmonizar ou atenuar uma circunstancia negativa encontrada nos conflitos diários. Ademais, não se trata mais da telas, mas das latas de tinta como suporte definitivo da obra; das cores internas das 


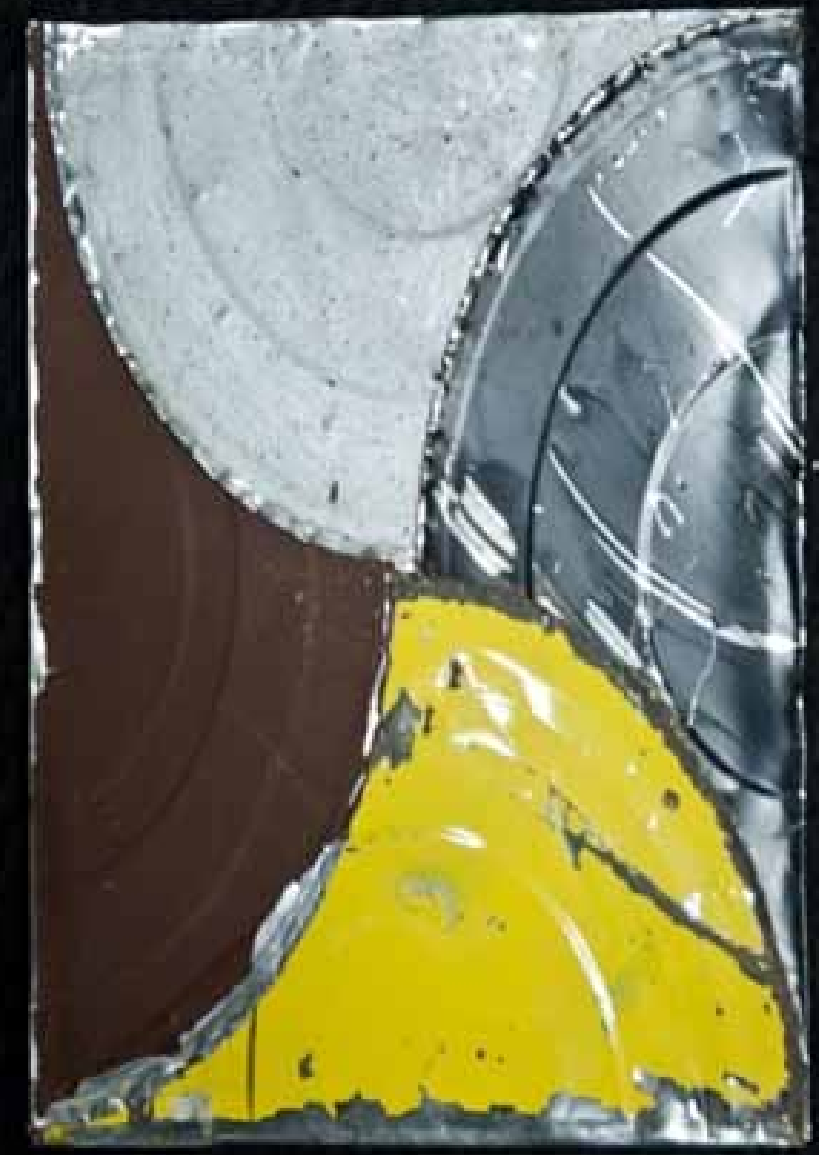

por uma Minimal Art hipotética. Mas, não é de Pop art nem de Minimal art que se trata. Essas possíveis esculturas planificadas cuja ação do tempo corroeu sua aura metálica, afirmam, mais do que nunca, a presença da terra, da poeira, dos ventos e de uma natureza brutalmente terrestre. Esses elementos reunidos constituem a marca de um tempo arquivado e impresso em pequenos, grandes e médios "latifúndios. A mesma lata que atrai a mão, também poderia feri-la através de seus contornos cortantes e irregulares que reforçavam a ideia de uma "geometria sensível" porém, reconciliadora da expressão individual, que longe de ser imperfeita e/ ou provisória procura dignificar o cotidiano e o aparentemente banal. 


\section{Notas}

1 MARX, Karl. O 18 Brumário de Louis Bonaparte. São Paulo: Centauro, 2006. p. 133.

2 Sobre a definição de estereótipo na construção do discurso do colonialismo afirma Bhabha: "O estereótipo não é uma simplificação porque é uma falsa representação de uma dada realidade. É uma simplificação porque é uma forma presa, fixa, de representação que, ao negar o jogo da diferença (que a negação através do Outro permite), constitui um problema para a representação do sujeito em significações de relações psíquicas e sociais". Cf. BHABHA, K. Homi. O local da cultura. Belo Horizonte: editora UFMG, 2010, p. 117. 3 Trecho de entrevista gravada e transcrita concedida à autora por Ronald Duarte em 05 de novembro de 2012 (documento inédito). 4 Trecho de entrevista gravada e transcrita concedida à autora por Raimundo Rodriguez, em 29 de Agosto de 2012 (documento inédito) 5 Sobre a construção de discursos críticos pós-coloniais afirma Homi Bhabha: "A perspectiva pós-colonial - como vem sendo desenvolvida por historiadores culturais e teóricos da literatura - abandona as tradições da sociologia do subdesenvolvimento ou teoria da "dependência". Como modo de análise, ela tenta revisar aquelas pedagogias nacionalistas ou "nativistas" que estabelecem a relação do Terceiro Mundo com o Primeiro Mundo em uma estrutura binária de oposição. A perspectiva pós-colonial resiste à busca de formas holísticas de explicação social. Ela força um reconhecimento das fronteiras culturais e políticas mais complexas que existem no vértice dessas esferas políticas frequentemente opostas." Cf. (BHABHA, 2010, p. 241-242).

6 Idem, Ibidem, p. 240.

7 "Sobras do mundo" é um termo poético usado de maneira recorrente na obra de Raimundo Rodriguez, refere-se à exposição homônima realizada pela primeira vez em 2000, em parceria com o artista visual Júlio Sekiguchi. A exposição de Raimundo Rodriguez e Julio Sekiguchi "Sobras do Mundo," foi realizada de 24 de outubro a 08 de novembro de 2000, na Galeria de Arte Toulouse, na Gávea, Rio de Janeiro. Os artistas desenvolveram, nesta ocasião, uma série de trabalhos a partir das, ditas, "sobras do mundo". As obras eram compostas por imagens, pensamentos, resíduos e vestígios. Todo tipo de marcas do tempo e de materiais adormecidos em estado banal, que remetessem às formas esgotadas ou desgastadas.

8 Sobre a instalação Babel, afirma Cildo Meireles em entrevista ao Jornal o Globo: "Fiz este trabalho com o objetivo de criar uma árvore falante. Dentro de um espaço escuro e barulhento torna-se real toda a informação e sensorialidade dos grandes centros urbanos. Babel é uma torre que talvez você mais sinta do que veja, aquela coisa da luzinha do rádio acesa no escuro do quarto está presente no ambiente da instalação." Entrevista publicada no Jornal O Globo online, em 02 Nov. 2006, concedida à jornalista Márcia Abos. Disponível em < http://oglobo.globo.com/cultura/mat/2006/11/02/286515302.asp> Acesso em 25 Ago. 2010.

9 ANJOS, Moacir dos. Arte Bra crítica. Rio de Janeiro: Automática, 2010. p. 81.

10 Idem. Ibidem. p. 83

11 Sobre o programa "Hora do Brasil": “Desde 1931, com o Departamento Oficial de Publicidade, substituído em 1934 pelo Departamento de Propaganda e Difusão Cutural (DPDC), o governo já vinha implantando uma política de controle da informação transmitida pelo rádio e pela imprensa. Quando o DPDC se transformou no Departamento Nacional de Propaganda (DNP), em 1938, inaugurou-se o programa "Hora do Brasil", transmitido diariamente por todas as estações de rádio, com duração de uma hora, visando à divulgação dos principais acontecimentos da vida nacional." Cf. Fundação Getúlio Vargas (CPDOC). Diretrizes do Estado Novo (1937 - 1945) > "Hora do Brasil". Disponível: < http://cpdoc.fgv.br/producao/dossies/AEraVargas1/anos37-45/EducacaoCulturaPropaganda/ HoraDoBrasil> Acesso em: 15 Mar. 2014. 
12 Entende-se por pintura de Color field o estilo de pintura plana e abstrata que se estabeleceu, sobretudo, em Nova York, durante os anos 40 e 50, inspirado nas vanguardas estéticas europeias e com uma aproximação ao expressionismo abstrato. A Color Field tem como um de seus principais representantes o artista americano Barnett Newman, apontado como um dos criadores do estilo. Nas palavras do historiador Edward Lucie-Smith, assim Newman definia o processo da Color Field, ou, da abstração pós-pictórica: "Por volta de 1950, ou seja, no auge do expressionismo abstrato, Newman já definiria seus objetivos. Ele queria organizar a superfície da pintura como um "campo" e não como uma composição, uma ambição que ia consideravelmente além de Pollock." Cf. SMITH-LUCIE, Edward. Os movimentos artísticos a partir de 1945. São Paulo: Martins Fontes, 2006. p. 74.

13 A noção de um campo expandido refere-se ao termo utilizado pelo historiador Michael Archer e que nomeia o segundo capítulo do livro "Arte contemporânea: Uma história concisa", significando uma análise histórica dos anos 60 e 70, a partir do afrouxamento das categorias tradicionais das Belas Artes, rumo à constituição de um campo maior e interdisciplinar que contextualizou o aparecimento de formas artísticas híbridas tais como: Arte Conceitual, Arte Povera, Processo, Anti-forma, Land Art, Ambiental, Body art, Performance e Política. Termo semelhante foi descrito por Rosalind Krauss em texto histórico intitulado "A escultura em campo ampliado", publicado originalmente em 1979, na revista October $n^{\circ} 8$.

Cf. ARCHER, Michael. O campo expandido. In: Arte Contemporânea: Uma história Concisa. São Paulo: Martins Fontes, 2001. p. 61-116.

Cf. KRAUSS, Rosalind. A escultura no campo ampliado. In: Arte \& Ensaios. Revista do Programa de Pós-Graduação em Artes Visuais. Rio de Janeiro: EBA-UFRJ, ano XIV, n 17, p. 128-137.

\section{Referências}

ANJOS, Moacir dos. Arte Bra crítica. Rio de Janeiro: Automática, 2010. Local/Global: arte em trânsito. Rio de Janeiro: Jorge Zahar Editor. 2005.

ARCHER, Michael. O campo expandido. In: Arte Contemporânea: Uma história Concisa. São Paulo: Martins Fontes, 2001.

BHABHA, K. Homi. O local da cultura. Belo Horizonte: editora UFMG, 2010.

A questão do "outro". Diferença, discriminação e o discurso do colonialismo. In: HOLLANDA, Heloisa, Buarque (org.). Pós-modernismo e política. Rio de Janeiro: Rocco, 1992. 177-203.

HALL, Stuart. A identidade cultural na pós-modernidade. Rio de Janeiro: Editora DP\&A, 1998.

Da Diáspora: Identidades e Mediações Culturais. Belo Horizonte: Ed. UFMG, 2003.

KRAUSS, Rosalind. A escultura no campo ampliado. In: Arte \& Ensaios. Revista do Programa de Pós-Graduação em Artes Visuais. Rio de Janeiro: EBA-UFRJ, ano XIV, $n^{\circ} 17$.

MARX, Karl. O 18 Brumário de Louis Bonaparte. São Paulo: Centauro, 2006.

SMITH-LUCIE, Edward. Os movimentos artísticos a partir de 1945. São Paulo: Martins Fontes, 2006. 